\title{
Evolutionary Quantum Technology: The Future with Holographic Plasma Voxel
}

Yogi Udjaja*

Computer Science Department, School of Computer Science, Bina Nusantara University, Jakarta, Indonesia 11480

A R T I C L E IN F O

Article history:

Received: 11 October, 2019

Accepted: 09 January, 2020

Online: 23 March, 2020

Keywords:

Evolution

Quantum Technology

Future

Holographic Plasma Voxel

Holography

Hologram Technology

User Experience
A B S T R A C T

This current situation will affect the future, technology models that are unthinkable or which impossible to happen pops up one by one. Like the hologram, this technology began to develop as a solution to increase user comfort in operating a system that is needed. This paper explains the development of hologram technology that is currently available and what the prediction of future technology models will be.

\section{Introduction}

The future is unpredictable, but by understanding the advantages that shape this period-one of them is the development of human education which gives rise to creativity that affects human and computer interactions-, based on this we can learn where to look for it and how to interpret what is found [1]. Many models have been found or developed from various researchers, such as algorithm optimization [2], skin cancer detection systems [3], learning applications for visually impaired children [4], making hydroponic tower systems for people want to plant with limited space [5], mathematics learning applications [6], recommendation system [7], website engine [8], strategic game experience [9-11], game for learning Japanese language $[12,13]$, improvement performance teacher system $[14,15]$, technology enhance learning system [16], cat disease detection system [17], determining teacher engagement [18], and much more.

The more days discoveries in the technology sector are increasing, it causes the order of life in the world such as lifestyle, education and all processes that occur change. One of the changes can be seen from the user experience, where there are many ways to present graphs in augmented reality and virtual reality.

"Yogi Udjaja, Jakarta, Indonesia 11480, +62 898268 3399,

udjaja.yogi@gmail.com, yogi.udjaja@binus.ac.id

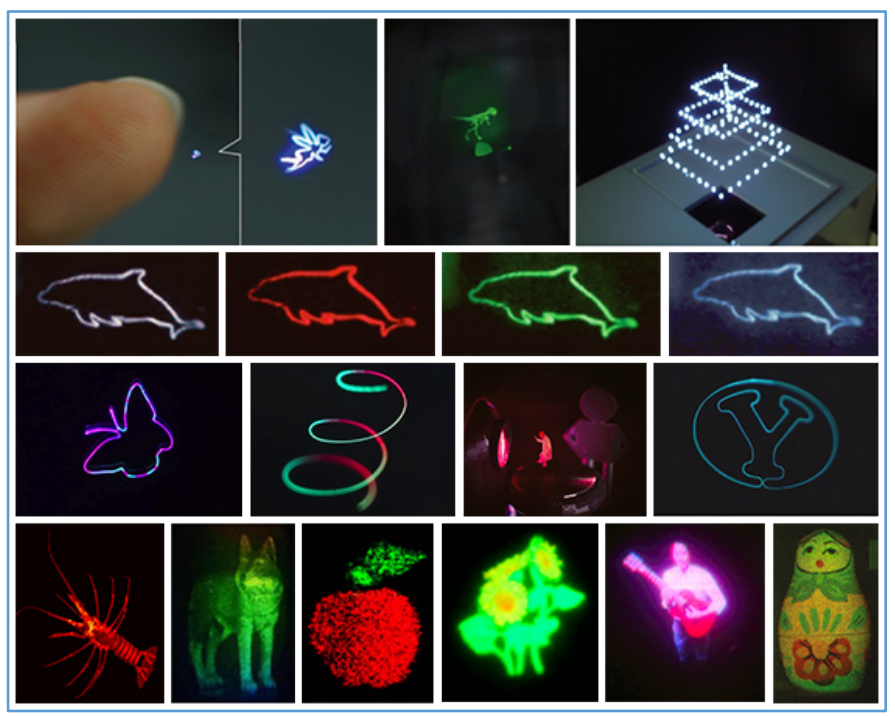

Figure 1: Holographic Projections

Presentation of the graph is currently still using a special device, experience still has discomfort in a physiological perspective [19]. Because of this, holographic display are developed, where the container used is air, as in figure 1 made by ref. [19-30]. The technique of making holograms is called holography, this technique has been widely used and developed by researchers, on 
the other hand the technology used is still not able to be used by the general public, because based on the size of the hardware and system it still requires a lot of development.

\section{History of Holography}

\subsection{Holography}

In 1947 the holography was discovered by Gabor [31], which produced random patterns of light intensity that varied spatially. Then in 1961 Leith and Upatnieks adopted the work of Gabor and applied it to laser beams free space and still produced the same model. It did not stop there, in 1966 found computer generated hologram (CGH) by Brown and Lohman, using numerical calculations to calculate wave phase information on the hologram interface can simplify the recording process through programming. This breakthrough opens up many new findings to create virtual objects that are seen in a real state but their forms do not exist in a static or dynamic state using spatial light modulators (SLM) [32].

Furthermore in 1982 Aspect et al. those from the University of Paris discovered subatomic particles in which electrons can connect to each other regardless of the distance that separates. This changed the world view of the principle held by Einstein, that no communication can travel faster than the speed of light, because when faster than the speed of light is the same as breaking the barrier of time [33].

The inventions continue to be developed, many physicists try to understand Aspect's findings, the results found a more radical explanation. Where according to one physicist from the University of London, Bhom explained that Aspect's findings do not have objective reality, apart from the solidity of the universe, subatomic particles can relate to each other apart from separate distances, where the separation produces an illusion called a hologram [33].

Currently holograms can be defined as three-dimensional images made based on interference patterns from coherent light waves (laser light) [34]. While the holography is a hologram making technique by recording and reconstructing the light wave fronts without amplifying and distributing the specified phase [35]. In making it, to form a hologram requires high-speed computing so that apropriate of the shapes and models are displayed as desired.

Based on previous research, a hologram is formed from the energy produced by a laser, the following are research has been done to make a hologram:

In Table 1 can be seen the research of Kimura et al. (2006) [20] and Saito et al. (2008) [21], produces 100 and $1000 \mathrm{Dot} / \mathrm{Sec}$, but has not been able to produce a hologram. Then in the study of Ochiai et al. (2016) holograms can be produced using femtosecond lasers with energies of $30-100 \mathrm{fs}, 2 \mathrm{~mJ}$ and $269 \mathrm{fs}$, $50 \mu \mathrm{J}$ with 1 color [22]. Then developed again by Hayasaki and Kumagai (2018), where the hologram has several colors produced from femtosecond lasers with energy $<100 \mathrm{fs}, 4.3 \mu \mathrm{J}$ [19] (see figure 1).

Table 1: Research to Produce Holographic Projections

\begin{tabular}{|c|c|c|c|}
\hline Researcher & $\begin{array}{l}\text { Type of } \\
\text { Laser }\end{array}$ & $\begin{array}{l}\text { Energy of } \\
\text { Laser }\end{array}$ & Dot/Sec \\
\hline al. (2006) & Nanosecond & Ns Normal & 100 \\
\hline Saito et al. (2008) & Femtosecond & $100 \mathrm{fs}$ & 1000 \\
\hline Ochiai et al. (2016) & Femtosecond & $30-100 \mathrm{fs}, 2 \mathrm{~mJ}$ & 1000 \\
\hline Ochiai et al. (2016) & Femtosecond & $269 \mathrm{fs}, 50 \mu \mathrm{J}$ & 200000 \\
\hline
\end{tabular}

\subsection{Voxel}

To display a hologram a volumetric approach is used with a predetermined diffraction pattern [36]. Literally a hologram is formed based on a dot produced from a laser beam that forms certain patterns (see figure 1). The element for the hologram is known as the volume pixel (voxel) - model 3D of pixels.

\subsection{Computer Generated Hologram}

Currently the technology for generating holograms has been widely circulated, such as: augmented reality (AR), virtual reality (VR) and mixed reality (MR) devices [37], but the technology can still cause vergence-accommodation disparity which can lead to inconvenience headache and nausea [36]. Then to avoid this, a holography technique called computer generated hologram (CGH) was developed using a laser beam.

The use of lasers is still a lot that can be developed, from the hardware and software side to security in use, because when playing with lasers can affect the health of the eyes and skin, if you do not use a protective eye and skin will be damaged.

In the Research Ochiai et al. (2016) suggest using anti-radiation glasses until this technology already has its own security, on the other hand it also documented several observations and studies when laser light exposed to the skin can also cause lesions, counted in $50 \mathrm{~ms}-6000 \mathrm{~ms}$ starting from small wounds up to $>2000 \mathrm{~ms}$ will burn skin surface [21]. This discovery is the same as the computer was first discovered, where it is still large in size, requires a large amount of money, is functional which is limited and difficult to carry everywhere. In accordance with the principle of calm technology, as time goes by all technology is made so that people do not realize that they are interacting with the technology itself [38].

\subsection{Spatial Light Modulator}

Spatial light modulator (SLM) is a dynamic device that can modify light according to the position of the object [39]. According to Ref. [39], there are 2 types of SLM, namely:

- Licuid Crystal on Silicon (LCoS)

As the name, this SLM uses birefringent liquid crystal molecules that are parallel because of the voltage applied to the electrode at the bottom.

- Micro-Opto-Electro-Mechanical Systems (MOEMS) MOEMS is a device that uses a micro-opto-mechanical element or like a mirror driven by electrical impulses. 


\section{Y. Udjaja / Advances in Science, Technology and Engineering Systems Journal Vol. 5, No. 2, 305-308 (2020)}

What is often investigated by researchers in the holography field is $\mathrm{LCoS}$, because $\mathrm{LCoS}$ can produce a holographic pattern with full wave changes. Each voxel can be arranged, so that luminous patterns can be displayed and direct energy in a certain order.

\subsection{Deep Learning}

Machine Learning is very useful for handling large-scale and high-dimensional data. There are several methods that support machine learning, one of the most prominent is the artificial neural network (ANN) [40]. ANN's extraordinary learning ability significantly outperforms conventional machine learning techniques. This has been proven in various disciplines.

As time goes by, because of the many human needs, then machine learning evolved into deep learning to solve existing problems. Deep learning is a representation learning method that has a level of representation starting from raw data into a complex composition of transformations and functions [41]. Where the architecture is a multilevel neural network, so that it can know more about something. As an example for the introduction of an object in an image, based on existing data deep learning is able to recognize shapes, know the name and position of objects in the image, and can predict events that will occur (Object detection, classification and prediction), besides that it can also be used to reconstruct and improve the quality of voxels so that images produced from $\mathrm{CGH}$ from low-quality resolution become highquality resolutions [42-49].

\section{Future Research and Experience System}

Holographic Plasma Voxel (HPV) is a naming taken from a plasma laser that produces a volume of pixels (Voxel) in the real world so that it forms a pattern that is currently called a hologram. This hologram technology is very useful for progress in various fields such as computer aided design, medical imaging and navigation [50]. In addition, this future technology is predicted to be used in the future as befits a smartphone that we use today, as everyone can interact directly with real entities and many applications such as education, games and others can be felt in real terms. For example in figure 1 there are several animal shapes that are made into holograms, the hologram can be further developed into a virtual pet for the introduction of animals to children or to eliminate phobias of animals.

\section{Discussion and Conclusion}

The evolution of time has made different holographic models, from one set of modes to another, where each newly emerging generation inherits the existing pattern from the previous one [51]. Over the past 70 years research has been carried out to produce holograms by reflecting light repeatedly using parallel mirrors. This has a tremendous impact, because it can fulfill all physiological aspects and provide a natural experience without causing visual fatigue because it does not use special devices such as glasses or other devices [52]. Until now this technology still being developed, and the phenomenon predicted by Enstein and other researchers is still being investigated. Based on the current situation, the law of causality is always in the investigation, this can be seen from the advantages and disadvantages of existing technology, all of which can be used as learning for the future.

\section{References}

[1] Grudin, J. (2018, April). From Tool to Partner: The Evolution of HumanComputer Interaction. In Extended Abstracts of the $2018 \mathrm{CHI}$ Conference on Human Factors in Computing Systems (p. C15). ACM.

[2] Girsang, A. S., Tanzil, F., \& Udjaja, Y. (2016, November). Robust adaptive genetic K-Means algorithm using greedy selection for clustering. In Knowledge, Information and Creativity Support Systems (KICSS), 2016 11 th International Conference on (pp. 1-5). IEEE.

[3] Udjaja, Y. (2018). ANDROID APPLICATION FOR DETECTION OF SKIN CANCER USING EXPERT SYSTEM. Social Economics and Ecology International Journal (SEEIJ), 2(1), 1-8.

[4] YanFi, Udjaja, Y., \& Sari, A. C. (2017). A Gamification Interactive Typing for Primary School Visually Impaired Children in Indonesia. Procedia Computer Science, 116, 638-644.

[5] Yunanto, A., Aslamiah, A. H., Darmawan, D., Santoso, I., \& Udjaja, Y. (2016). PENGEMBANGAN EKONOMI SOSIAL DALAM SEKTOR PERTANIAN DENGAN MENGGUNAKAN HYDROPONIC TOWER SYSTEM.

[6] Udjaja, Y., Guizot, V. S., \& Chandra, N. (2018). Gamification for Elementary Mathematics Learning in Indonesia. International Journal of Electrical and Computer Engineering (IJECE), 8(6).

[7] Gunawan, F. E., Maryanto, A., Udjaja, Y., Candra, S., \& Soewito, B. (2016, November). Improvement of E-learning quality by means of a recommendation system. In Knowledge, Information and Creativity Support Systems (KICSS), 2016 11th International Conference on (pp. 1-4). IEEE.

[8] Udjaja, Y. (2018). EKSPANPIXEL BLADSY STRANICA: Performance Efficiency Improvement of Making Front-End Website Using Computer Aided Software Engineering Tool. Procedia Computer Science, 135, 292301.

[9] Kristiadi, D. P., Udjaja, Y., Supangat, B., Prameswara, R. Y., Warnars, H. L. H. S., Heryadi, Y., \& Kusakunniran, W. (2017, November). The effect of UI, UX and GX on video games. In Cybernetics and Computational Intelligence (CyberneticsCom), 2017 IEEE International Conference on (pp. 158-163). IEEE.

[10] Sasmoko, Halim, S. A., Indrianti, Y., Udjaja, Y., Moniaga, J., \& Makalew, B. A. (2019, March). The Repercussions of Game Multiplayer Online Battle Arena. In 2019 International Conference of Artificial Intelligence and Information Technology (ICAIIT) (pp. 443-447). IEEE.

[11] Sasmoko, Harsono, J., Udjaja, Y., Indrianti, Y., \& Moniaga, J. (2019, March). The Effect of Game Experience from Counter-Strike: Global Offensive. In 2019 International Conference of Artificial Intelligence and Information Technology (ICAIIT) (pp. 374-378). IEEE.

[12] Udjaja, Y. (2018). Gamification Assisted Language Learning for Japanese Language Using Expert Point Cloud Recognizer. International Journal of Computer Games Technology, 2018.

[13] Udjaja, Y., Renaldi, Steven, Tanuwijaya, K., \& Wairooy, I. K. (2019). The Use of Role Playing Game for Japanese Language Learning. Procedia Computer Science, 157, 298-305.

[14] Sasmoko, Indrianti, Y., Widhoyoko, S. A., Udjaja, Y., \& Tanurwijaya, A. (2018, August). Teacher Engagement Interventions through ITEI Apps. In 2018 6th International Conference on Cyber and IT Service Management (CITSM) (pp. 1-4). IEEE.

[15] Sasmoko, Indrianti, Y., Widhoyoko, S. A., Udjaja, Y., \& Rosyidi, U. (2018, August). Performance Change With or Without ITEI Apps. In 2018 6th International Conference on Cyber and IT Service Management (CITSM) (pp. 1-4). IEEE.

[16] Udjaja, Y., Indrianti, Y., Rashwan, O. A., \& Widhoyoko, S. A. (2018, October). Designing Website E-Learning Based on Integration of Technology Enhance Learning and Human Computer Interaction. In 2018 2nd International Conference on Informatics and Computational Sciences (ICICoS) (pp. 206-212). IEEE.

[17] Aulia, A., Udjaja, Y., Wairooy, I. K., Hutama, A. P., Shabira, D. K., \& Muhtadin, S. Android Application to Detect Cat Disease Using an Expert System.

[18] Sasmoko, Moniaga, J., Indrianti, Y., Udjaja, Y., \& Natasha, C. (2019, July). Designing Determining Teacher Engagement Based on The Indonesian Teacher Engagement Index Using Artificial Neural Network. In 2019 International Conference on Information and Communications Technology (ICOIACT) (pp. 377-382). IEEE. 


\section{Y. Udjaja / Advances in Science, Technology and Engineering Systems Journal Vol. 5, No. 2, 305-308 (2020)}

[19] Hayasaki, Y., \& Kumagai, K. (2018, June). Volumetric display with holographic femtosecond laser accesses. In Digital Holography and ThreeDimensional Imaging (pp. DTu5F-1). Optical Society of America.

[20] Kimura, H., Uchiyama, T., \& Yoshikawa, H. (2006, July). Laser produced 3D display in the air. In ACM SIGGRAPH 2006 emerging technologies (p. 20). ACM.

[21] Saito, H., Kimura, H., Shimada, S., Naemura, T., Kayahara, J., Jarusirisawad, S., ... \& Asano, A. (2008, February). Laser-plasma scanning 3D display for putting digital contents in free space. In Stereoscopic Displays and Applications XIX (Vol. 6803, p. 680309). International Society for Optics and Photonics.

[22] Ochiai, Y., Kumagai, K., Hoshi, T., Rekimoto, J., Hasegawa, S., \& Hayasaki, Y. (2016). Fairy lights in femtoseconds: aerial and volumetric graphics rendered by focused femtosecond laser combined with computational holographic fields. ACM Transactions on Graphics (TOG), 35(2), 17.

[23] Ochiai, Y. (2016, May). 8-4: Invited Paper: Pixels towards Pixies: PostMultimedia interactions with Air-Based Media. In SID Symposium Digest of Technical Papers (Vol. 47, No. 1, pp. 79-82).

[24] Yamada, S., Kakue, T., Shimobaba, T., \& Ito, T. (2018). Interactive holographic display based on finger gestures. Scientific reports, 8(1), 2010.

[25] Smalley, D. E., Nygaard, E., Squire, K., Van Wagoner, J., Rasmussen, J., Gneiting, S., ... \& Costner, K. (2018). A photophoretic-trap volumetric display. Nature, 553(7689), 486.

[26] Im, D., Cho, J., Hahn, J., Lee, B., \& Kim, H. (2015). Accelerated synthesis algorithm of polygon computer-generated holograms. Optics Express, 23(3), 2863-2871.

[27] Choo, H. G., Chlipala, M., \& Kozacki, T. (2019). Visual perception of Fourier rainbow holographic display. ETRI Journal.

[28] Huang, Z., Marks, D. L., \& Smith, D. R. (2019). Out-of-plane computergenerated multicolor waveguide holography. Optica, 6(2), 119-124.

[29] Bianco, V., Memmolo, P., Leo, M., Montresor, S., Distante, C., Paturzo, M., ... \& Ferraro, P. (2018). Strategies for reducing speckle noise in digital holography. Light: Science \& Applications, 7(1), 48.

[30] Kim, J., Lim, Y., Hong, K., Kim, H., Kim, H. E., Nam, J., ... \& Kim, Y. J. (2019). Electronic Tabletop Holographic Display: Design, Implementation, and Evaluation. Applied Sciences, 9(4), 705.

[31] Shimobaba, T., \& Ito, T. (2019). Computer Holography: Acceleration Algorithms and Hardware Implementations. CRC Press.

[32] Huang, L., Zhang, S., \& Zentgraf, T. (2018). Metasurface holography: from fundamentals to applications. Nanophotonics, 7(6), 1169-1190.

[33] Talbot, M. (1991). The holographic universe.

[34] Awad, A. H., \& Kharbat, F. F. (2018, February). The first design of a smart hologram for teaching. In Advances in Science and Engineering Technology International Conferences (ASET), 2018 (pp. 1-4). IEEE.

[35] Cviljušac, V., Divjak, A., \& Modrić, D. (2018). Computer Generated Holograms of 3D Points Cloud. Tehnički vjesnik, 25(4), 1020-1027.

[36] Khan, J., Blackwell, C., Can, C., \& Underwood, I. (2018, May). 16-1: Invited Paper: Holographic Volumetric 3D Displays. In SID Symposium Digest of Technical Papers (Vol. 49, No. 1, pp. 177-180).

[37] El Saddik, A. (2018). Digital Twins: The Convergence of Multimedia Technologies. IEEE MultiMedia, 25(2), 87-92.

[38] Poslad, S. (2011). Ubiquitous computing: smart devices, environments and interactions. John Wiley \& Sons.

[39] Collier, R. (2013). Optical holography. Elsevier.

[40] Jo, Y., Cho, H., Lee, S. Y., Choi, G., Kim, G., Min, H. S., \& Park, Y. (2019). Quantitative phase imaging and artificial intelligence: a review. IEEE Journal of Selected Topics in Quantum Electronics, 25(1), 1-14.

[41] LeCun, Y., Bengio, Y., \& Hinton, G. (2015). Deep learning. nature, 521(7553), 436.

[42] Thanh, N., Xue, Y., Li, Y., Tian, L., \& Nehmetallah, G. (2018). Deep learning approach to Fourier ptychographic microscopy. Optics Express.

[43] Shimobaba, T., Endo, Y., Nishitsuji, T., Takahashi, T., Nagahama, Y., Hasegawa, S., ... \& Ito, T. (2018). Computational ghost imaging using deep learning. Optics Communications, 413, 147-151.

[44] Göröcs, Z., Tamamitsu, M., Bianco, V., Wolf, P., Roy, S., Shindo, K., ... \& Ozcan, A. (2018). A deep learning-enabled portable imaging flow cytometer for cost-effective, high-throughput, and label-free analysis of natural water samples. Light: Science \& Applications, 7(1), 66.

[45] Liu, T., de Haan, K., Rivenson, Y., Wei, Z., Zeng, X., Zhang, Y., \& Ozcan, A. (2019). Deep learning-based super-resolution in coherent imaging systems. Scientific reports, 9(1), 3926.

[46] Sun, Y., Xia, Z., \& Kamilov, U. S. (2018). Efficient and accurate inversion of multiple scattering with deep learning. Optics express, 26(11), 1467814688 .
[47] Metzler, C., Schniter, P., \& Veeraraghavan, A. (2018, July). prDeep: Robust phase retrieval with a flexible deep network. In International Conference on Machine Learning (pp. 3498-3507).

[48] Shimobaba, T., Takahashi, T., Yamamoto, Y., Endo, Y., Shiraki, A., Nishitsuji, T., ... \& Ito, T. (2019). Digital holographic particle volume reconstruction using a deep neural network. Applied optics, 58(8), 19001906.

[49] Zhang, H., Fang, C., Xie, X., Yang, Y., Mei, W., Jin, D., \& Fei, P. (2019). High-throughput, high-resolution deep learning microscopy based on registration-free generative adversarial network. Biomedical Optics Express, 10(3), 1044-1063.

[50] St-Hilaire, P., Benton, S. A., Lucente, M. E., Jepsen, M. L., Kollin, J., Yoshikawa, H., \& Underkoffler, J. S. (1990, May). Electronic display system for computational holography. In Practical Holography IV (Vol. 1212, pp. 174-183). International Society for Optics and Photonics.

[51] Dvali, G. (2018). A Microscopic Model of Holography: Survival by the Burden of Memory. arXiv preprint arXiv:1810.02336.

[52] Isomae, Y., Shibata, Y., Ishinabe, T., \& Fujikake, H. (2017). Design of 1$\mu \mathrm{m}$-pitch liquid crystal spatial light modulators having dielectric shield wall structure for holographic display with wide field of view. Optical Review, 24(2), 165-176. 